\title{
Social Aspects of Behavioural Problems in Rural School Age Children
}

\section{IJCRR}

Section: Healthcare

Sci. Journal Impact

Factor: 6.1 (2018)

ICV: 90.90 (2018)

\section{P. M. Durgawale, Mrs. Supriya S. Patil, R. V. Mohite}

Department of Community Medicine Krishna Institute of Medical Sciences Deemed To Be University, Karad, India.

(c) (1) (8)

Copyright@IJCRR

\section{ABSTRACT}

Introduction: Social problems are the result of the failure of society to adapt to its social institutional culture to its growing needs. Social problems, therefore, are man-made. They are one of the major sources of social suffering.

Aim: The study was aimed to find out the prevalence of behavioural problems in rural school-age children and to study social factors associated with behavioural problems in children.

Methods: A community-based cross-sectional study was conducted in a rural field practice area. All children of age 6-15 years were included in the study, Mothers were the informant. A manual for the Behaviour Checklist and Revised Child Behaviour profile was used to collect data. Data were summarized in number and percentages. Chi-square test was applied to assess association if exists between social factors and behavioural problems.

Results: Total 456 children were studied from the age group of 6-15 years. Majority of the children were from the age group of $12-15$ i.e. 254 (55.7\%) children. Male children constituted 298 (65.35\%). Majority of the children were enrolled in school 449 (98.5\%), Major proportion of study group constitute children from joint families i.e. $410(89.9 \%)$ and only 46 (10.1\%) were from nuclear families. There were $138(30.3 \%)$ children with behavioural problems coming from two children families. Majority of the parents were from high school grade education 158(34.6\%). Occupation of the father was $264(57.89 \%)$ farmer in the majority of the children. Prevalence of the behavioural problem were Conduct disorder 358(78.5\%), Attention deficit hyperactivity disorder 309(67.8\%), Anxiety disorder 415(91.8\%), Oppositional defiant disorder 367(80.5\%), Depressive disorder 355(77.7\%), Obsessive-compulsive disorder 33(7.2\%), Gender Identity Disorder 2(0.4\%).

Conclusion: Timely prevention and timely intervention of these behaviour problems can decrease the burden of future psychiatric morbidity or criminality on society.

Key Words: Behavioural Problems, Rural Area, School Age, Conduct disorder, Attention deficit.

\section{INTRODUCTION}

Social problems are the result of the failure of society to adapt to its social institutional culture to its growing needs. Social problems, therefore, are man-made. They are one of the major sources of social suffering. The lives of all members of a social group are directly or indirectly affected by this suffering. All members of society have to pay and must be made to pay in some form or other for these social deficits and breaches in the social order. The man from his very infancy goes after security. The greater the social gulf, within the society, lesser is the social security and greater the personal and social disorganization. Irrespective of the causes of social inequality or unequal distribution of opportunity, the fact remains that every social group has members whose plight calls for serious public attention and vigorous social action to cement the breach sand overcome the deficits to restore a state of social equilibrium within the society. A realization of this type is possible with a sympathetic attitude supported by scientific understanding of nature, extent, social diagnosis and therapeutic action to resolve a social problem ${ }^{1}$.

Furthermore, the experience of the past offers only indirect aid to understanding and grappling with today's large scale problems. It is little wonder, therefore that so many of our thinkers and writers view the present-day situation with profound apprehension. Some feel that the unprecedented development and expansion on the material side of culture has

\section{Corresponding Author:}

Dr. Mrs. Supriya S. Patil, Department of Community Medicine Krishna Institute of Medical Sciences Deemed To Be University, Karad, India. Email: hodpsm@kimskarad.in

ISSN: 2231-2196 (Print)

Received: 24.07 .2020
ISSN: $0975-5241$ (Online)

Revised: 22.08 .2020
Accepted: 18.09 .2020 
already reached a crisis and that further progress is hardly possible until non-material culture, especially the spiritual forces which form the sound basis of human relationships have had a chance to grow and develop accordingly ${ }^{2}$.

Children less than 15 years constitute $40 \%$ of the country's population and by nature of their unique vulnerability are more susceptible to stressors but less likely to seek treatment. Mental ill-health in children is a frequent precursor of limited functional capacities in adulthood. A sick child is likely to grow into a sick adult. Incorporation of well being of child's mental health into Government institutional and family policies can significantly improve child-rearing practices which in turn influences the response of the family, the teacher and the medical personnel to child-related stressors and behaviour ${ }^{3}$.

It is also well known that there is an intimate relationship between physical and mental health. Physical disorders have emotional consequences and mental disorders can frequently present as physical symptoms which if not recognized can lead to frequent inappropriate unnecessary, wasteful and frustrating medical interventions. There is a need for doctors especially at primary level to be aware of behaviour problems presenting as somatic complaints ${ }^{4}$.

This is also applicable in the schools. A child may be unable to obtain full benefits from education if he is suffering from physical or mental illness, which is again related to each other. Studies targeting school populations have created an awareness of behavioural problems causing poor performance in school children. Teachers can play a significant role in helping the child, referring the child for the management or advising the parents about effective ways of improving a child's functioning 5 .

Prevalence of mental disorders in children in developing countries may be as common as in developed countries. Mental disorders are unique in that their presentation is significantly influenced by the cultural factors and there is a different presentation of various disorders in different countries. Malhotra and Malhotra found that developmental conflicts faced by Indian Children were different from those reported from the west ${ }^{6}$.

The current scenario indicates that there is a need for a study that will assess the prevalence of behaviour problems and study social factors that contribute to the occurrence and persistence of behaviour problems. Because of all these factors, the current study was undertaken.

\section{AIMS OF THE STUDY}

1. To assess the prevalence of behavioural problems in rural school-age children.
2. To study social factors associated with behavioural problems in children.

\section{MATERIAL AND METHOD}

\section{Study Area}

The study was conducted after ethical clearance from the institutional ethics committee in a rural field practice area.

\section{Study subjects}

All children of age 6-15 years were included in the study.

\section{Type of study}

A community-based cross-sectional study.

\section{Informant}

Mothers were chosen as they are universally available, are most knowledgeable about their child, are almost always involved in evaluation and treatment, have views of their child's behaviour which is crucial in determining what will be done about a problem and are important in determining whether further help will be sought.

\section{A tool to assess the child behavioural problem} The Child Behaviour Check List [CBCL]:-

A manual for the Behaviour Checklist and Revised Child Behaviour profile was used to collect data of each child, which also provides standardized procedures for the parents for reporting problems of children. ${ }^{7}$

\section{Analysis}

Data were summarized in number and percentages. Chisquare test was applied to assess association if exists between social factors and behavioural problems.

\section{Observations}

Age - sex distribution of study subjects shows that out of 456 children, 298 were male and 158 were female children. Majority of the children were from joint family 410 (89.9\%). There were 449 (98.5\%) study subjects enrolled in the school.

\section{Education of the Parents of study subjects}

The higher proportion of high school grade education $213(46.7 \%)$ followed by primary grade education $158(34.6 \%)$.

\section{Occupation of Father of the study subjects}

Farmer $264(57.89 \%)$ followed by skilled worker 127 $(27.85 \%)$ and unemployed only $4(0.87 \%)$. 
Total number of children in the family

In the present study, a higher proportion of families with two children were seen in majority i.e. 138 (30.3\%)

\section{Living Status of Parents of study subjects}

The present study reveals the observation that parents 450 (98.7\%) of both father and mother were alive and living with their children was seen.

\section{Family History}

Mental Retardation: Only one family was observed with the history of mental retardation in the present study

\section{Regular alcohol consumption by the Father of the study subjects}

The habit of regular alcohol consumption by father was present in $172(37.7 \%)$ families.

\section{CONDUCT DISORDER}

In the age group 6-11 years, a higher proportion of male children 87 (79.1\%) were having Conduct Disorder $\left(\chi^{2}=1.474\right.$, $\mathrm{p}>0.05$ ) and in the age group 12-15 years female children $54(81.8 \%)$ were having a higher proportion of Conduct Disorder $\left(\chi^{2}=0.071, \mathrm{p}>0.05\right)$. There was no significant difference observed in the proportion of male and female conduct disorder. According to the distribution of table, among $172(100.0 \%)$ families were having a history of consumption of alcohol by father in which $145(84.3 \%)$ children were having conduct disorder problem. There was a significant association between alcoholism in parents and the prevalence of conduct disorder problem in children.

\section{Attention deficit hyperactivity disorder (ADHD)}

In the age group 6-11 years, higher proportion of male children 73 (66.4\%) were having ADHD $\left(\chi^{2}=0.242, p>0.05\right)$ and also in 12-15 years age group higher proportion of male children $135(71.8 \%)$ of ADHD $\left(\chi^{2}=1.032, \mathrm{p}>0.05\right)$ were seen. There was no significant difference observed in the proportion of male and female ADHD. While comparing with the age, the higher proportion was seen in 12-15 age group 178 (70.1\%). However, there was no significant difference observed in both the age group in $\operatorname{ADHD}\left(\chi^{2=1.407, p>0.05)}\right.$

\section{Anxiety Disorder (AD)}

In the age group 6-11 years, higher proportion of male children $105(95.5 \%)$ were having $\operatorname{AD}\left(\chi^{2}=4.694, \mathrm{p}<0.05\right)$ and in 12-15 years age group higher proportion of female children $59(89.4 \%)$ were having $\operatorname{AD}\left(\chi^{2}=0.643, \mathrm{p}>0.05\right)$. There was a significant difference observed in the proportion of male and female AD in 6-11 years age group. While comparing with the age, the higher proportion was seen in 12-15 age group 233(91.7\%). However, there was no significant difference observed in both the age group in $\operatorname{AD}\left(\chi^{2}=0.003, \mathrm{p}>0.05\right)$

\section{Oppositional Defiant Disorder (ODD)}

In the age group 6-11 years, higher proportion of male children $93(84.5 \%)$ were having $\operatorname{ODD}\left(\chi^{2}=5.676, \mathrm{p}<0.05\right)$ and in $12-15$ years age group higher proportion of female children $55(83.3 \%)$ were having $\operatorname{ODD}\left(\chi^{2}=0.067, \mathrm{p}>0.05\right)$. There was a significant difference observed in the proportion of male and female ODD in 6-11 years age group. While comparing with the age, the higher proportion was seen in 12-15 age group $209(82.3 \%)$. However, there was no significant difference observed in both the age group in $\operatorname{ODD}\left(\chi^{2}=1.184, \mathrm{p}>0.05\right)$

\section{Depressive Disorder (DD)}

In the age group 6-11 years, higher proportion of female children $70(76.1 \%)$ were having $\operatorname{DD}\left(\chi^{2}=0.159, \mathrm{p}>0.05\right)$ and in 12-15 years age group higher proportion of male children $152(80.9 \%)$ were having $\operatorname{DD}\left(\chi^{2}=0.132, \mathrm{p}>0.05\right)$. There was no significant difference observed in the proportion of male and female DD in 6-11 years age group. While comparing with the age, the higher proportion was seen in 12-15 age group $204(80.3 \%)$. However, there was no significant difference observed in both the age group in $\operatorname{DD}\left(\chi^{2}=2.019, \mathrm{p}>0.05\right)$.

\section{Obsessive-Compulsive Disorder (OCD)}

In the age group 6-11 years, higher proportion of male Children $11(10.0 \%)$ were having $\operatorname{OCD}\left({ }^{2}=5.096, \mathrm{p}<0.05\right)$ and in 12-15 years age group higher proportion of female children $152(80.9 \%)$ were having $\operatorname{OCD}\left(\chi^{2}=0.182, \mathrm{p}>0.05\right)$. There was a significant difference observed in the proportion of male and female OCD in 6-11 years age group. While comparing with the age, the higher proportion was seen in 12-15 age group $20(07.9 \%)$. However, there was no significant difference observed in both the age group in OCD $\left(\chi^{2}=0.347\right.$, $\mathrm{p}>0.05$ )

\section{Gender Identity Disorder (GID)}

In the age group 6-11 years, one male child (09\%) was having GID $\left(\chi^{2}=0.841, \mathrm{p}>0.05\right)$ and in $12-15$ years age group one male child $(05 \%)$ was having $\operatorname{GID}\left(\chi^{2}=0.352, \mathrm{p}>0.05\right)$. While comparing with the age, no significant difference observed in both the age group in GID $\left(\chi^{2}=0.026, p>0.05\right)$

\section{Prevalence of behavioural problems}

The prevalence of the behaviour problem was seen in higher proportion in Anxiety Disorder (91.8\%), followed by ODD (80.5\%), $\mathrm{CD}(78.5 \%), \operatorname{DD}(77.7 \%), \operatorname{ADHD}(67.8 \%)$, $\operatorname{OCD}(7.2 \%)$ and the lowest proportion of behaviour problem was seen in Gender Identity Disorder (0.4\%).

\section{DISCUSSION}

The study group comprised of children of age group 6-15 years. It was further divided into two age groups viz 6-11 years and 12-15 years. 
Prevalence as well as the pattern of behaviour problems varied according to age group. The 12-15 years age group was influenced by various biological changes like hormonal fluctuations and neurobiochemical changes. Similarly, the peer pressure, family and school environment and other external environmental factors influenced the behaviour pattern differently in different age groups ${ }^{8}$. The behaviour problem thus being peculiar the study group was divided into two groups i.e. $6-11$ and $12-15$ years.

In the present study, the majority of children belonged to age group 12-15 years i.e. $254(55.7 \%)$ with male preponderance $298(65.75 \%)$

Majority of the children were from age group 6-10 years i.e. $40.8 \%$ and from $11-14$ years $41.9 \%$. Thus male to female ratio was 3:2 showing the male preponderance ${ }^{8}$. Sarita Bhargava also found the majority of male children i.e. $70 \%$ in her study ${ }^{9}$. Majority 410(89.9\%) of the children were from joint family indicated a high proportion of children from joint families in the study area.

However, Abraham Vergese observed $82 \%$ of the study group belonged to nuclear families ${ }^{10}$. Also, P.K.Singhal et al found $72.3 \%$ predominance of the nuclear family. In these studies, the area selected was a clinic-based urban area. The predominance of nuclear families may be because the majority of the families migrated from rural area to urban area in search of work or educational purposes. Secondly, the family structure is changing more in favour of nuclear set up ${ }^{11}$.

As the present study was done in a rural area, the main occupation was agriculture and work-related with it. it is seen that the enrollment of the child in the school was $98.5 \%$ with no dropouts, remaining $1.5 \%$ of children were never enrolled in the school. While considering the education of parents, higher education of one of the parents was recorded; when both were educated. The higher proportion of education was seen in high school grade $(46.7 \%)$ followed by primary school education (34.6\%).

Children with conduct disorder were seen in a high proportion $(78.5 \%)$ in both the age groups. In the 6-11 years age group, the prevalence was $75.7 \%$ and in $12-15$ years it was $80.7 \%$. Higher prevalence was seen in the higher age group.

M Bhallaet al. found $11 \%$ of children with conduct disorder in 8-12 years age group with male preponderance. ${ }^{12}$

McGee TR found most of the children with antisocial problems in the age group of 15-18 years and classified them as having theft and vandalism in 39\% children; physical fights and destructiveness in 34\% children at age of 13-14 years and $1 \%$ children who had convicted crime ${ }^{13}$.

In Attention deficit hyperactivity disorder (ADHD), the male children in both age groups were having a slightly higher proportion of ADHD problem. In different types of the
ADHD problem, majority of the response was given to the no-61(poor schoolwork) 208(45.6\%) and no-10 (the child was hyperactive or restless) $124(27.2 \%)$. The overall prevalence of ADHD was (67.8\%) 309 .

Col S Choudhary et al found ADHD 24(11.28\%) which was very low compared to the present study. It was due to the study carried in child guidance clinic, urban area; and also because the different classification was used to carry out the study ${ }^{14}$.

The anxiety disorder (AD) showed a higher proportion of male children in the 6-11 age group which was a significant and higher proportion of female children in the 12-15 age group. In different types of Anxiety disorder majority of the response was given to no47-(nightmare) 238(52.8\%), no-37 (gets into many fights) 224(49.1\%), no-95 (temper tantrum or hot temper) 198(43.4\%) and no-86(stubborn, sullen or irritable 163(35.7\%).

There was no significant association seen between family types, occupation of the father with AD. However, a significant association was seen between parents with middle school and primary school education and alcoholism in father with $\mathrm{AD}$.

Srinath et al. observed an overall prevalence of educational problems in $27.09 \%$ in her study conducted in 4-16 years age group at Bangalore. ${ }^{15}$

Choudhary et al found OCD 2(0.47\%) which was very low compared to the present study. It was due to the study carried in "child guidance clinic", urban area; and different classification was used to carry out the study. ${ }^{14}$

The male preponderance observed in the study may be due to the patriarchal pattern of the society in India. Most of the times males are purposively neglected for their misbehaviour as considering the normal behaviour for his gender. Some researchers mentioned that these gender differences might occur due to hiding information by parents about the misbehaviour of daughter due to social and cultural factors in the community.

Alcoholism is now a day increasing in India. The increased economic pressure and indulged in heavy working makes this sector of the population involved in alcoholism. A range of emotional and behavioural effects have been linked with parental alcoholism particularly childhood antisocial behaviour, depression and anxiety. ${ }^{16}$

\section{CONCLUSION}

The factors which were found to be associated with the prevalence of behaviour problems are modifiable and hence the behaviour problems have good progress. Timely prevention and timely intervention of these behaviour 
problems can decrease the burden of future psychiatric morbidity or criminality on society.

\section{ACKNOWLEDGEMENT}

Authors acknowledge the immense help received from the scholars whose articles are cited and included in references to this manuscript. The authors are also grateful to authors/ editors/publishers of all those articles, journals and books from where the literature for this article has been reviewed and discussed

Conflict of interest: Nothing to report.

Source of funding: KIMSDU karad

\section{REFERENCES}

1. Madan GR. Indian Social Problems (Vol-1): Social Disorganization and Reconstruction. Allied Publishers; 1966 Jul 2.

2. Buss AR. Psychology in a social context. New York: Irvington Publishers; 1979.

3. Zeitlin H. Children with alcohol misusing parents. British Medical Bulletin. 1994;1;50(1):139-51.

4. Durgawale, P. M., Patil, S. V., \& Shinde, M. B. Nutritional assessment of school-going children (6-11 years) in an urban slum of Karad, dist. Satara. International Journal of Advanced Science and Technology,2020; 29(4): 1198-1203.

5. Dalal M, Kapur M, Kaliaperumal V. Prevalence and pattern of psychological disturbance in school-going adolescent girls. Indian J Clin Psychol. 1990;17:83-8.

6. Naregal, P. M., Durgawale, P. M., Shinde, M. B., \& Kakade, S. V. "Effectiveness of Planned Teaching Programme on Mother's
Knowledge On Factors Affecting Nutritional Status of PreSchool Children (3-5years) Attending Anganwadi in Selected Urban Slum Areas of Karad". International Journal of Advanced Science and Technology, 2020;29(4): 1246-1253.

7. Achenbach TM, Edelbrock CS. Psychopathology of childhood. Annual review of psychology. 1984;35(1):227-56.

8. Malhotra S, Chaturvedi SK. Patterns of childhood psychiatric disorders in India. The Indian Journal of Pediatrics. 1984;51(2):235-40.

9. Bhargava S, Garg OP, Singhi S, Singhi P, Lall KB. Prevalence of behaviour problems in Ajmer school children. The Indian Journal of Pediatrics. 1988;55(3):408-15.

10. Verghese A, Beig A. Psychiatric disturbances in children. An epidemiological study Indian J Med Res, 1974; 62 (10):1538-1548

11. Peterson AL, Campise RL, Azrin NH. Behavioural and pharmacological treatments for tic and habit disorders: A review. Journal of Developmental and Behavioral Pediatrics. 1994;15(6):43041.

12. Bhalla M, Bhalla JN, Mahendru RK, Singh KB, Singh SB. Psychiatric disorders among children attending pediatric OPD. Indian paediatrics. 1986;23(8):623-6.

13. McGee TR, Hayatbakhsh MR, Bor W, Aird RL, Dean AJ, Najman JM. The impact of snares on the continuity of adolescentonset antisocial behaviour: A test of Moffitt's developmental taxonomy. Australian \& New Zealand Journal of Criminology. 2015;48(3):345-66.

14. Chaudhury S, Prasad PL, Zacharias R, Madhusudan T, Saini R. Psychiatric morbidity pattern in a child guidance clinic. Medical Journal Armed Forces India. 2007;63(2):144-6.

15. Lesinskiene S, Girdzijauskiene S, Gintiliene G, Butkiene D, Puras D, Goodman R, Heiervang E. Epidemiological study of child and adolescent psychiatric disorders in Lithuania. BMC public health. 2018;18(1):1-8.

16. Jijina P, Sinha UK. Parent Assisted Social Skills Training for Children with Attention Deficit Hyperactivity Disorder. Journal of the Indian Academy of Applied Psychology. 2016;42(2):299. 